\title{
Using Cloud Computing in Higher Education: A Strategy to Improve Agility in the Current Financial Crisis
}

\author{
Marinela Mircea and Anca loana Andreescu \\ Academy of Economic Studies, Bucharest, Romania
}

\begin{abstract}
In the current financial crisis and being challenged by growing needs, universities are facing problems in providing necessary information technology (IT) support for educational, research and development activities. The objective of this paper is to find alternatives to the use of IT, while leading universities to improve agility and obtain savings. The research methodology consisted in a rigorous analysis of the latest research on Cloud Computing as an alternative to IT provision, management and security. It also took into account the best practices for Cloud Computing usage within universities, plus the authors' experience in IT and higher education. The article begins with a brief introduction to Cloud Computing in universities, referring to the most important results obtained so far. Further, a starting point for universities to use Cloud Computing is provided, by proposing an adoption strategy. The strategy includes five stages, with emphasis on the evaluation of data and processes/functions/applications from several major universities based on some key criteria, while creating a correspondence between these aspects and the models/services/applications that exist on the Cloud market. The results obtained are encouraging and support the use of Cloud solutions in universities by improving knowledge in this field and providing a practical guide adaptable to the university's structure. In order to be applicable in practice, the proposed model takes into account the university's architecture and criteria such as mission, availability and importance of applications and also the data's mission, sensitivity, confidentiality, integrity and availability.
\end{abstract}

Keywords: Cloud Computing, higher education, cloud strategy, agility

\section{Introduction}

Higher education was acknowledged in time as one of the pillars of society development. Through the partnerships between universities, government and industry, researchers and students have proven their contribution to the transformation of society and the entire world economy (Lazowska et al., 2008). The tendency observed during the last few years within the higher education level (Mircea, 2010; Bozzelli, 2009), is the universities' transition to research universities and ongoing update of the IT (Information Technology) infrastructure as foundation for educational activities and Science research. With the evolution of technology, the number of services which migrate from traditional form to the online form grows as well. For these specific services, an adequate providing form must be found in the online environment, using the

Copyright (C) 2011 Marinela Mircea and Anca Ioana Andreescu. This is an open access article distributed under the Creative Commons Attribution License unported 3.0, which permits unrestricted use, distribution, and reproduction in any medium, provided that original work is properly cited. Contact author: Marinela Mir, email:mmircea@ase.ro 
proper technologies, guaranteeing the access of large number of users, fast and secure payment services (Ivan et al., 2009).

Due to this aspect, at the moment universities are confronting with a dramatic increase of costs in higher education, more than the inflation rate (Golden, 2010) and a decrease of universities' budgets, which leads to the pressure of finding some alternative means of reaching their purpose i.e. the education of students and accomplishing the research. As a response to these pressures, the universities must perform changes in order to be service oriented and in order to optimize the efficiency and effectiveness of all internal operations and of all interactions with the main stakeholders (Mircea and Andreescu, 2010). Service orientation may be applied to individuals (including roles, capabilities and characteristics), to universities (in terms of strategy, structure, culture and processes), but also to technology (according to the semantics, applications, architecture and infrastructure of modern institutions).

At the organization level, Cloud Computing may be considered an extension of SOA (Service Oriented Architecture) (Mircea et al., 2011) and an alternative to the use of IT for educational environment, especially in the conditions of the present financial crisis. From this point of view it is important to identify data, services, and processes that are suitable candidates to reside in the Cloud. Without SOA, migrating towards cloud has no sense from the financial point of view.

\section{Using Cloud Computing in Higher Education}

The potential and efficiency of using Cloud Computing in higher education has been recognized by many universities among which we mention University of California, Washington State University's School of Electrical Engineering and Computer Science, higher education institutions from UK, Africa (Sultan, 2010), U.S and others. Cloud Computing offers to universities the possibility of concentrating more on teaching and research activities rather than on complex IT configuration and software systems (McCREA, 2009), through a fast IT implementation. According to Tout et al., 2009 complexity can be reduced with Cloud Computing.

In addition, cloud solutions can be used to support cooperative learning and socially oriented theories of learning, using computer technologies to support collaborative methods of instruction (Thorsteinsson et al., 2010). Cloud computing offers many benefits to e-learning solutions by providing the infrastructure, platform and educational services directly through cloud providers and by using virtualization, centralized data storage and facilities for data access monitoring (Pocatilu et al ., 2009). In order to ensure success in e-learning, universities use metrics systems adapted to measure the effectiveness of e-learning solutions based on the cloud.

Currently, there are many practices and examples regarding the use of cloud computing. For instance, in Commonwealth, many colleges and universities had collaborated at the formation of Virginia Virtual Computing Lab (Wyld, 2009). This allowed institutions both to cut down IT expenses (by reducing the necessities of licensing and software updating) and to maintain its own data centers, as well as to improve IT resources for researches and students. By including the cloud services, North Carolina State University achieved a substantially decreasing of expenses with software licensing and at the same time to reduce the campus IT staff from 15 to 3 employees with full working schedule (Wyld, 2009). Another example is Kuali Ready (Bristow et al., 2010), a community-source project chartered to provide a business continuity planning service and it is also an example of higher education institutions organizing themselves to provide cloud services. Kuali Ready is a good early example of some key principles that are emerging to guide cloud developments. 
Within the present economical context, the use of Cloud Computing becomes a necessity and not an option for many universities. This aspect is due to a multitude of factors such as costs increase, the pressure of income increase, students' success, institutional performance and competition in development (Sasikala and Prema, 2010). Nevertheless, a recent study with respect to using Cloud Computing in higher education, shows that universities may still be found in the phase of "early adopters" next to other sectors, such as commercial and governmental (Katz et al., 2010). The significant factors that influence the decision of using Cloud Computing in higher education differ a little from other sectors. Thus, according to Katz et al (2010), 70\% of the IT leaders from higher education (from 302 survey respondents) have considered that improving IT services is the most important decision factor, while only $38 \%$ gave the same importance to costs reduction.

\section{Main Benefits, Risks and Limitations}

The use of Cloud Computing in higher education must be analyzed both from the benefits point of view, as well as from that of the risks and limitations (table 1). After the analysis, one or more models of Cloud Computing may be chosen to be used. The decision must take into account the real needs and be aligned with the university strategy.

Table 1: Main Benefits and Limitations of Using Cloud Computing in Higher Education

\begin{tabular}{|l|l|}
\hline Benefits & Limitations \\
\hline Access to applications from anywhere & Not all applications run in cloud \\
\hline Support for teaching and learning & $\begin{array}{l}\text { Risks related to data protection and security } \\
\text { and accounts management }\end{array}$ \\
\hline Software free or pay per use & Organizational support \\
\hline $\begin{array}{l}24 \text { hours access to infrastructure and } \\
\text { content }\end{array}$ & Dissemination politics, intellectual property \\
\hline $\begin{array}{l}\text { Opening to business environment and } \\
\text { advanced research }\end{array}$ & Security and protection of sensitive data \\
\hline $\begin{array}{l}\text { Protection of the environment by using } \\
\text { green technologies }\end{array}$ & Maturity of solutions \\
\hline $\begin{array}{l}\text { Increased openness of students to new } \\
\text { technologies }\end{array}$ & Lack of confidence \\
\hline Increasing functional capabilities & Standards adherence \\
\hline $\begin{array}{l}\text { Offline usage with further synchronization } \\
\text { opportunities }\end{array}$ & $\begin{array}{l}\text { Speed/lack of Internet can affect work } \\
\text { methods }\end{array}$ \\
\hline
\end{tabular}

The decision taking of using Cloud Computing must also take into account the risks of non-implementing,, but also the implementation risk associated to the solution. By implementing the solution a gain that exceeds the capital costs and compensates the associated risks must be obtained. Many of the risks specific to cloud environment may be transferred to cloud providers. As mentioned in Patterson (2010), many of the risks specific to cloud environment may be transferred to cloud providers. As regards the implementation risks, a research conducted by the IDC Enterprise Panel (NIST, 2009) concluded that the primary concerns about adoption in higher education are: security, performance and availability, not enough ability to customize, worried on-demand will cost more, bringing back in-house may be difficult, regulatory requirements prohibit cloud, and not enough major suppliers yet. 
From the specific Cloud Computing types of risks (detailed in Catteddu and Hogben, 2009), we shall emphasize the security and data protection risks. The transfer of the research results and the knowledge between cloud and networks and moving the knowledge to external providers may become an attractive target to attackers (Tout et al., 2009). These aspects, according to a study conducted by EDUCAUSE based on 372 member institutions (Goldstein, 2009), are considered top barriers. Likewise, approximately $75 \%$ of Chief Information Officer and IT specialists consider security as being the number one risk (Jitterbit, 2009). The most important risks regarding security are: loss of governance, lock-in, isolation failure, compliance risks, management interface compromise, data protection, insecure or incomplete data deletion, and malicious insider (Catteddu and Hogben, 2009). Out of these, the protection of intellectual property and of the data in cloud represents the main preoccupation of the clients According to Spínola (2009), the protection of intellectual property and of the data in cloud represents the main preoccupation of the clients.

With respect to data protection, special attention must be paid to the sensitive data from the institution (for example, research results, students' scholastic records, employees' accounts). The main options that may be taken regarding data are:

- maintain the sensitive data within the institution data centers and externalize the others with the risk of achieving a high latency for many applications and users;

- externalize all the data in order to obtain performance and maximum scalability with potential security risks.

Currently there are many solutions for ensuring security and protection of sensitive data in cloud. Out of these, we mention (Luther, 2009; Mcirvine, 2010; SafeNet, 2010):
(1 mask or de-identify of the data;

2 firewalls;

3 encryption and key management;

4 federated identity management.

When choosing the data protection and security solution, the risks and costs on/non implementation must be taken into account, as well as the benefits of using the respective solution. Data encryption is the simplest solution of data protection against the unauthorized access in the cloud environment. Data may be encrypted at the moment of their collection or before their transfer in the cloud environment. Still, the most adequate solution would be a combination because options 2 and 3 do not address two important challenges (Luther, 2009): the challenge of knowing where all your sensitive data resides and the reality that encrypted data must at some point be unencrypted.

As a conclusion of the strong and weak aspects of Cloud Computing in universities, we may say that the payment per use model and the management policies of risks and security represent positive factors in taking the decision of using Cloud Computing. Moreover, Cloud Computing adds value with small capital expenses, assuring at the same time the protection of the environment. In the end, universities may value the opportunities offered by Cloud Computing through researchers and students and thus leading to innovation.

\section{Cloud Architecture for University}

Thinking, planning, and working in the cloud requires universities to cope with specific challenges of cloud environment (Bristow et al., 2010) such as uncertain definitions, privacy, contractual and jurisdictional issues, risk and nonperformance, interoperability, network capacity, rearchitecting, staff and perceptions. Also, the adoption of cloud 
architecture involves overcoming barriers, such as: policy and control issues, new services that will move above campus before older self-operated services, using an "accidental strategy" formed around consumer choice (Katz et al., 2009), organizational culture and regulatory considerations (Katz et al., 2010).

The adoption process of cloud architecture differs depending on the business segments. According to Katz et al., 2010 “...Research university CIOs may come to embrace a "get big or get out" ethos. Some will explore becoming centers of excellence (and providers) for some elements of the IT portfolio, while sourcing other elements elsewhere. Smaller IT operations are likely to become consumers of cloud services." The architectural pattern of using Cloud Computing in universities may be described starting from the development and supply of Cloud Computing services and the resources offered to the university (figure 1).

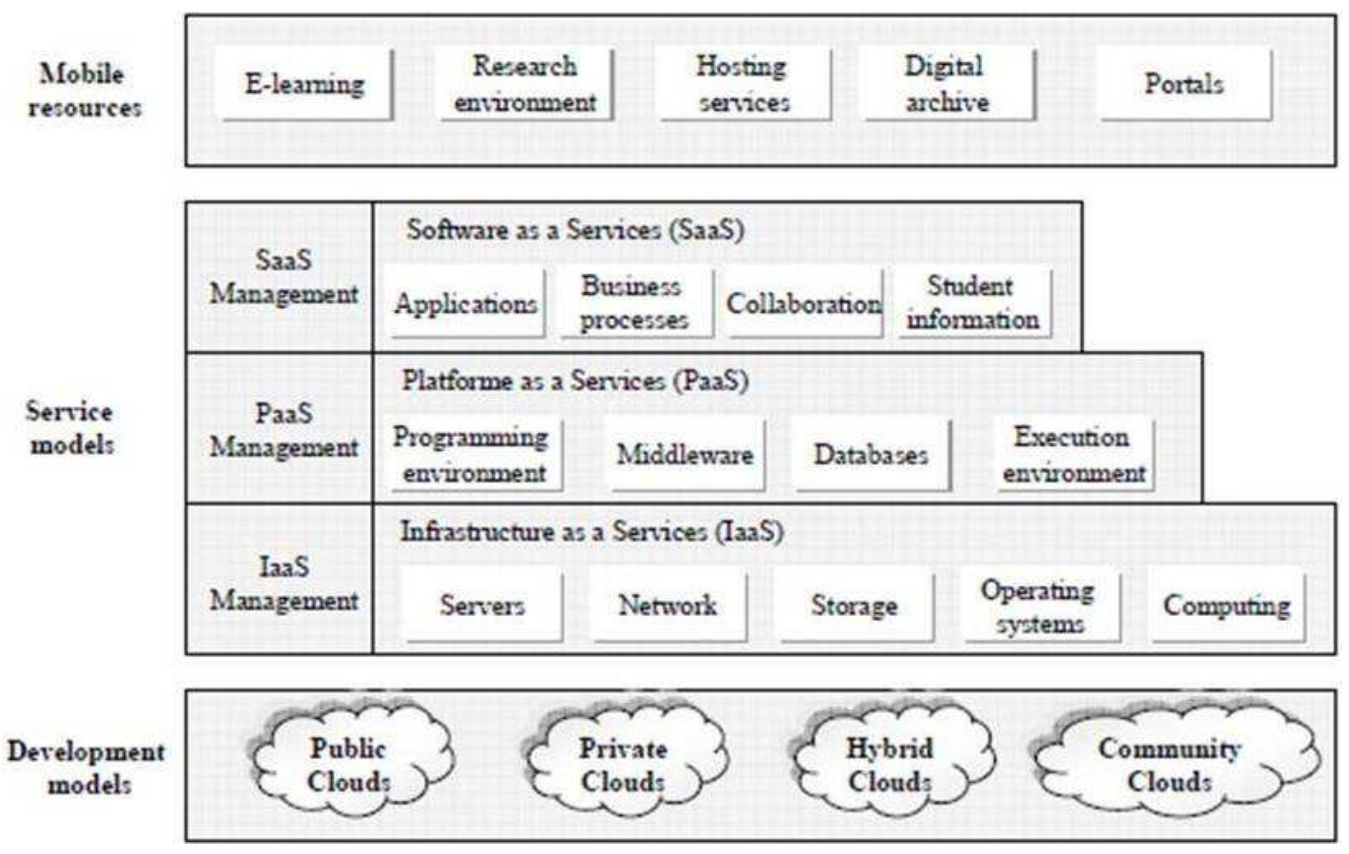

Fig 1 Cloud Architecture for University

With respect to cloud models, the main differences between public and private in the educational environment are presented in table 2. Hybrid models are also used (for example, Panasas private cloud combined with Amazon public cloud storage) as well as community ones (for example Virginia Virtual Computing Lab).

Table 2: Main Differences between Public and Private Cloud

\begin{tabular}{|l|l|l|}
\hline $\begin{array}{l}\text { Model } \\
\text { Feature }\end{array}$ & Public & Private \\
\hline Owned and managed & Service provider & University \\
\hline Access & By subscription & $\begin{array}{l}\text { Limited to students, } \\
\text { faculty, staff of the } \\
\text { university }\end{array}$ \\
\hline Customization and control & None & Yes \\
\hline
\end{tabular}


The community models appeared due to the increase of pressure in the educational environment (necessity of drawing up reports, monitoring educational, demographic and financial information starting from the moment of registering students and until the end of the educational stage) and also due to the advantages offered by collaboration (evaluating success on the labor market, emphasizing the educational quality, innovation). In some regions or countries, information is aggregated in centralized recordings about the student's qualifications, employment rates on various activity domains, results obtained by researchers. Creating reports and tendency analysis (Mircea et al., 2010) shall lead to well-founded decisions with respect to disciplines included in the curricula, specialties from the institution level, creating and/or canceling some master programs based on the identified needs. The next process illustrates the method in which a service consumer (the student) may access and modify information in a community cloud (figure 2).

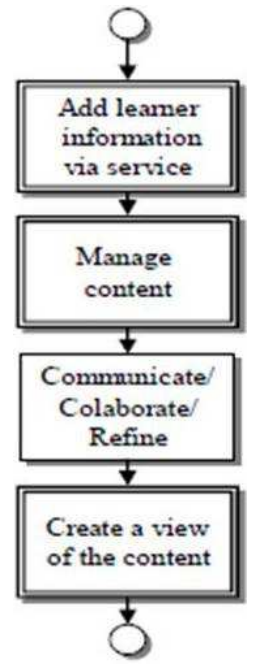

Fig 2. Student Adds Information about Their Learning in the Community Cloud

The successful use of Cloud Computing in higher education presupposes the existence of three key elements, namely virtualization, the intelligence from the network and a robust ecosystem (Bozzelli, 2009). These offer the basis for obtaining operational efficiency, security, activity continuance, scalability, interoperability leading in the end to innovation. In addition, a government involvement in organizing a centralized cloud at the level of higher education may stabilize the academic field (Sasikala and Prema, 2010) and lead to fast results in research and innovation.

\section{A Cloud Adoption Strategy for Higher Education}

Migrating towards cloud needs a welldefined strategy that supports Cloud Computing capabilities. Representing an important part of the organization IT strategy (Sheelvant, 2009), migration must be aligned to this. The success of the strategy implementation depends on the existence of a service-oriented architecture at the level of the institution that offers the necessary infrastructure for cloud implementation. Without SOA and BPM (Business Process Management), migrating towards cloud has no sense from the financial point of view because it leads to high costs with re- 
engineering of existent systems (Kavis, 2009). Also, in order to have success, the cloud strategy must be aligned with the university strategy. Starting from the recent researches related to the transition to Cloud Computing and the experience of universities in using it, we suggest a migrating strategy towards cloud, formed of the following stages (figure 3):

a) developing the knowledge base about Cloud Computing; b) evaluating the present stage of the university from the point of view of the IT needs, structure and usage;

c) experimenting the Cloud Computing solutions;

d) choosing the Cloud Computing solution;

e) implementation and management of the Cloud Computing solution.

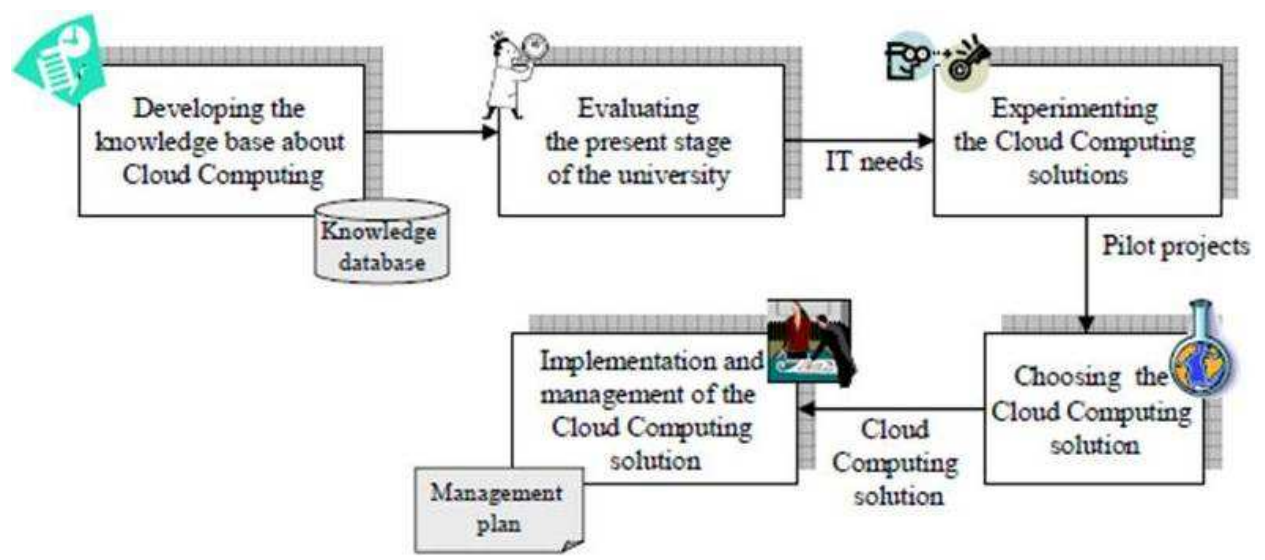

Fig 3. Cloud Strategy in Higher Education

a) Developing the knowledge base about Cloud Computing. The first step consists in developing the knowledge base by participating at seminaries, conferences, discussions with the suppliers and consulting the most recent researches in the field. The success of the phase depends on the allocation of sufficient resources for research, for understanding how Cloud Computing functions in different organizational structures from universities and between institutions (Wyld, 2009), the benefits and risks, policies and the best usage practices of Cloud Computing. The research is conducted by a team formed mainly of IT staff who permanently communicates with the users of the solution regarding the objectives, the progress, costs and benefits of the Cloud Computing solution.

b) Evaluating the present stage of the university from the point of view of the IT needs, structure and usage. The first step consists in understanding the university IT infrastructure. The service oriented architecture represents the base for understanding the data, services, processes and applications that may be migrated or need to be maintained within the university, so as to observe the security policy. With respect to the IT needs, their structure and usage, the analysis may start from the categories of users who interact with the present IT infrastructure (figure 4) and their necessities. 


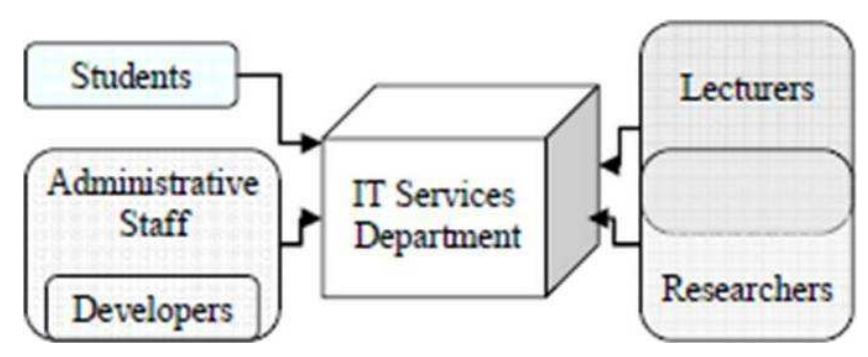

\section{Fig 4. Simplified Structure of the Main Users of IT Services in a Typical University}

The Cloud Computing solution will allow to all categories of users access to stored files, e-mail, database and other applications from anywhere at request (Nicholson, 2009), which leads to a more efficient use of information. This represents a transition from remote services offered to users in the traditional version to assuring some "selfservice" systems, which is beneficial in the Cloud Computing perspective.
The objective is to identify the emergent technologies, efficient from the point of view of costs that satisfy the necessities of the students and university staff. The hardware and software needs shall then be analyzed from the perspective of the three cloud models (figure 5).

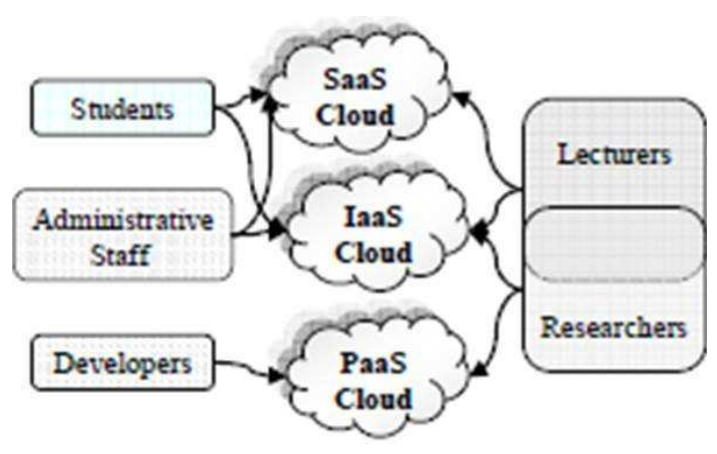
Fig 5. Simplified Structure of the Main Users of IT Services in a Typical University Now Using
the Services of Cloud Computing

Students already use many of the cloud technologies in their personal life (Ercan, 2010). By using a cloud model and applications based on cloud, they obtain the advantage of the ability of working and communicating in the educational environment without taking into account space and time. The teaching staff shall benefit of support in preparing their teaching portfolio (Thomas, 2009) (presentations of lessons, conferences, articles, etc.), in teaching practice (methods and teaching techniques, study materials, feedback) and in evaluating (methods and techniques of evaluation and management of the results). Researchers will benefit from the advantage of using the latest technologies, experimenting the results and communication, while paying for using this services.

Developers may design, build and test applications that are executed on the infrastructure of the cloud provider and deliver those applications directly from the servers of the provider to the final users (Wyld, 2009). System administrators obtain general processing, storage, database 
management and other resources and applications through the network. The rest of the administrative staff will benefit from services and infrastructure 24/24, from everywhere at low costs.
At present, the Cloud Computing market is continuously growing (see the existent solutions in Brunette and Mogull, 2009). Out of the existent solutions of Cloud Computing, we enumerate a few of the most used solutions in universities, grouped according to the three supply models (figure 6).

\begin{tabular}{|c|c|c|}
\hline $\begin{array}{l}\text { Platform Services } \\
\text { - Google App Engine } \\
\text { - Microsoft Azure Services } \\
\text { - Amazon SimpleDB } \\
\text { - Microsoft SDS } \\
\text { - Oracle Higher Education } \\
\text { Constituent Hub } \\
\text { - Amazon SQS } \\
\text { - Dynamsoft } \\
\text { - Force.com } \\
\text { - Microsoft Dynamics } \\
\text { CRM online }\end{array}$ & \multicolumn{2}{|c|}{$\begin{array}{l}\text { Software Services } \\
\text { - Google App } \\
\text { - Microsoft Dynamics CRM online } \\
\text { - Microsoft Live a edu } \\
\text { - Business Producivity Online Suite } \\
\text { - Exchange Hosted Services } \\
\text { - Microsoft Office Web Apps } \\
\text { - CampusEAI } \\
\text { - Jaspersoft } \\
\text { - EducationERP.net } \\
\text { - Campus Management } \\
\text { - Coupa's e-Procurement }\end{array}$} \\
\hline \multicolumn{3}{|c|}{ Infrastructure Services } \\
\hline $\begin{array}{l}\text { - EducationERP.net } \\
\text { - Amazon S3, EBS, EC2 } \\
\text { - Microsoft } \\
\text { - Flexiscale, GoGrid }\end{array}$ & $\begin{array}{l}\text { - Rackspace } \\
\text { - RightScale } \\
\text { - EnStratus } \\
\text { - CloudStatus }\end{array}$ & $\begin{array}{l}\text { - Oracle Coherence } \\
\text { - 3Tera App Logic } \\
\text { - Eucalyptus } \\
\text { - CampusEAI }\end{array}$ \\
\hline
\end{tabular}

Fig 6. Cloud Taxonomy

c) Experimenting the Cloud Computing solutions. The transition to cloud may be achieved gradually, starting from testing a pilot project in cloud and then externalizing the applications chosen for cloud. The first step consists of settling some cloud targets, such as development and environment testing or storing some data inside the cloud. The next step may consist of the daily processing of the internal operations, addressing at the same time the components of public and private cloud in order to assure the security and protection policies (Bozzelli,
2009). The maintenance of low costs for using the solution must be permanently taken into account.

d) Choosing the Cloud Computing solution. The first step consists of identifying the data (figure 7) and applications, functions and main processes within the university. These may be grouped according to the three large categories of activities from the university: teaching, research and administrative support for the first two activities. 


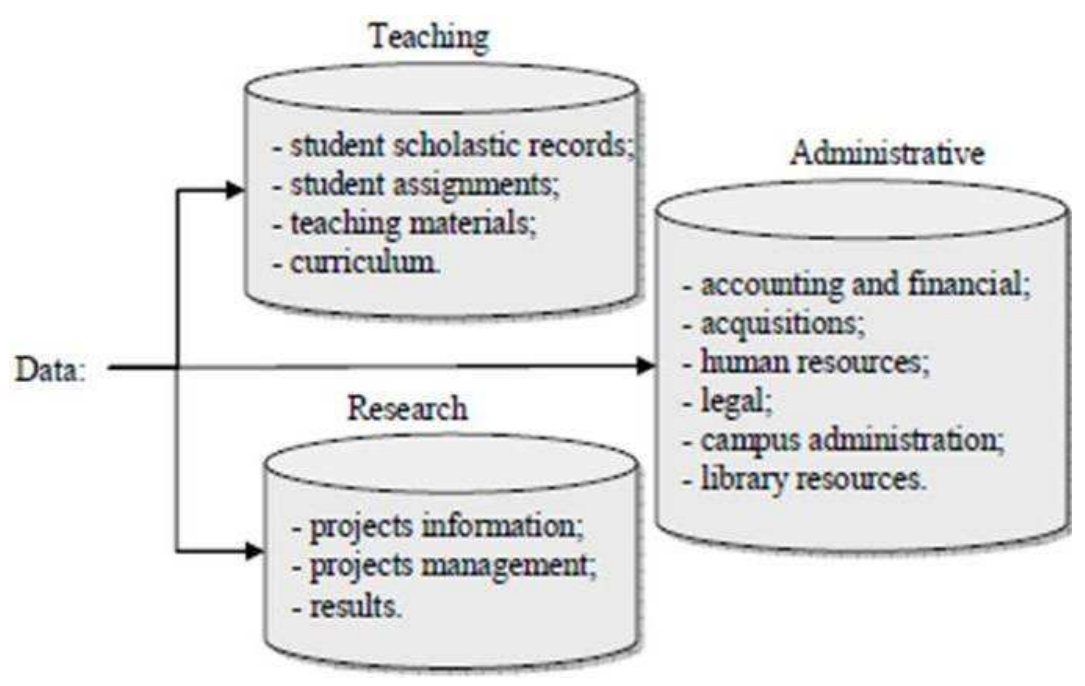

Fig 7. Main Data in a University

Step two is represented by the evaluation of the elements identified in the first step according to several criteria, such as mission, importance within the university, sensitivity, confidentiality, integrity, availability, in order to determine the candidate elements for cloud. As exemplification, we present an evaluation of the main elements within the university using an evaluation scale from 0 to 3 , with the following meaning: 0 - none, 1 low, 2 - medium and 3 - high (tables 3 and 4).

Table 3: Data Evaluation

\begin{tabular}{|l|l|l|l|l|l|}
\hline Data & $\begin{array}{l}\text { Mission } \\
\text { critical }\end{array}$ & Sensitivity & $\begin{array}{l}\text { Confidentialit } \\
\mathbf{y}\end{array}$ & $\begin{array}{l}\text { Integrit } \\
\mathbf{y}\end{array}$ & Availability \\
\hline Student scholastic records & 2 & 3 & 1 & 3 & 2 \\
\hline Student assignments & 1 & 0 & 2 & 3 & 2 \\
\hline Teaching materials & 0 & 1 & 2 & 1 & 2 \\
\hline Curriculum & 1 & 0 & 0 & 1 & 2 \\
\hline Projects information & 2 & 1 & 0 & 2 & 2 \\
\hline Projects management & 2 & 1 & 2 & 3 & 3 \\
\hline Results & 2 & 3 & 2 & 2 & 2 \\
\hline Accounting and financial & 3 & 3 & 3 & 3 & 3 \\
\hline Acquisitions & 2 & 1 & 1 & 3 & 3 \\
\hline Human resources & 1 & 1 & 2 & 2 & 1 \\
\hline Legal & 1 & 2 & 3 & 2 & 2 \\
\hline Campus administration & 1 & 1 & 2 & 2 & 2 \\
\hline Library resources & 1 & 1 & 0 & 1 & 2 \\
\hline
\end{tabular}

Applications shall be grouped and evaluated starting with the main activities specific to the university (the educational activity and support activities). 
Table 4: Activities Evaluation

\begin{tabular}{|l|l|l|l|}
\hline Functions/Processes/Applications & $\begin{array}{l}\text { Mission } \\
\text { critical }\end{array}$ & $\begin{array}{l}\text { Importanc } \\
\text { e }\end{array}$ & Availability \\
\hline Business Intelligence & 3 & 2 & 2 \\
\hline Academic Student Lifecycle & 2 & 3 & 3 \\
\hline E-learning & 1 & 3 & 3 \\
\hline Admission process & 3 & 2 & 3 \\
\hline Research projects management & 2 & 3 & 3 \\
\hline Accounting and financial processes & 3 & 1 & 3 \\
\hline Human resources management & 1 & 1 & 2 \\
\hline Acquisition process & 2 & 2 & 3 \\
\hline Case management & 1 & 1 & 3 \\
\hline Building administration & 2 & 2 & 2 \\
\hline Digital library & 1 & 1 & 2 \\
\hline
\end{tabular}

The last step consists of choosing the Cloud model (private, public, community, and hybrid) for each of the functions, processes and applications identified. The main identification criteria of the candidate applications to Cloud are considered the mission and importance of business practices (Spínola, 2009) (table 5). Considering the fact that most organizations use hybrid patterns of Cloud, maintaining key elements from their infrastructure in house, under direct control and externalizing less sensitive components, a strategic analysis must be conducted in order to choose the implementation solution regarding the decisions of integration/migration.

Table 5: Cloud Model Selection Criteria

\begin{tabular}{|l|l|l|}
\hline $\begin{array}{l}\text { Business } \\
\text { practices } \\
\text { Mission }\end{array}$ & Non-core & Core \\
\hline $\begin{array}{l}\text { Non-mission- } \\
\text { critical }\end{array}$ & $\begin{array}{l}\text { Public } \\
\text { clouds }\end{array}$ & $\begin{array}{l}\text { Private cloud } \\
\text { or non-cloud }\end{array}$ \\
\hline Mission-critical & $\begin{array}{l}\text { Public } \\
\text { clouds }\end{array}$ & $\begin{array}{l}\text { Private cloud } \\
\text { or non-cloud }\end{array}$ \\
\hline
\end{tabular}

Based on the observations from tables 3-5 and the experience of universities in implementing various cloud solutions, we propose the approach depicted in figure 8. 


\begin{tabular}{|c|c|c|c|c|c|c|c|c|c|c|c|c|}
\hline $\begin{array}{c}\text { Cloud } \\
\text { service }\end{array}$ & $\begin{array}{l}\text { Cloud } \\
\text { model }\end{array}$ & Solutions & $\begin{array}{c}\text { Business } \\
\text { Intelligence }\end{array}$ & $\begin{array}{c}\text { Student } \\
\text { Lifecycle }\end{array}$ & E-learning & Admission & $\begin{array}{c}\text { Accounting } \\
\text {-financial }\end{array}$ & $\begin{array}{l}\text { Human } \\
\text { resonces }\end{array}$ & Aquisition & $\begin{array}{c}\text { Case } \\
\text { management }\end{array}$ & \begin{tabular}{|c|} 
Building \\
administration
\end{tabular} & $\begin{array}{l}\text { Digital } \\
\text { library }\end{array}$ \\
\hline Saas & Poblic & MicrosoftLive@edu & & & $\checkmark$ & & & & & & & \\
\hline Saas & Poblic & $\begin{array}{l}\text { Microsoft Office Live } \\
\text { Workspace }\end{array}$ & & & $\checkmark$ & & & & & $\checkmark$ & & \\
\hline $\begin{array}{l}\text { Saas } \\
\text { Paas }\end{array}$ & $\begin{array}{l}\text { Private } \\
\text { Hybrid }\end{array}$ & $\begin{array}{l}\text { Microsoft Dynamics } \\
\text { CRM Online }\end{array}$ & & $\checkmark$ & & $\checkmark$ & & $\checkmark$ & & $\checkmark$ & & \\
\hline $\begin{array}{l}\text { Saas } \\
\text { Iaas }\end{array}$ & Private & $\begin{array}{l}\text { CampusEAI Private } \\
\text { Cloud }\end{array}$ & & $\checkmark$ & $\checkmark$ & $\checkmark$ & & & & & & \\
\hline $\begin{array}{l}\text { Saas } \\
\text { Iaas }\end{array}$ & $\begin{array}{l}\text { Private } \\
\text { Hybrid }\end{array}$ & $\begin{array}{l}\text { Jaspersoft and } \\
\text { RightScale }\end{array}$ & $\checkmark$ & & & & & & & & & \\
\hline Saas & Public & Google Docs & & & $\checkmark$ & & & & & $\checkmark$ & & \\
\hline $\begin{array}{l}\text { Saas } \\
\text { laas }\end{array}$ & $\begin{array}{c}\text { Private } \\
\text { Community }\end{array}$ & educationERP net & & $\checkmark$ & & $\checkmark$ & & $\checkmark$ & & & & $\checkmark$ \\
\hline Saas & $\begin{array}{l}\text { Private } \\
\text { Community }\end{array}$ & Campus management & $\checkmark$ & $\checkmark$ & $\checkmark$ & $\checkmark$ & $\checkmark$ & $\checkmark$ & & $\checkmark$ & $\checkmark$ & \\
\hline Saas & Private & Coupa e-Procurement & & & & & & & $\checkmark$ & & & \\
\hline
\end{tabular}

\section{Fig 8. Cloud Solutions for Higher Education}

e) Implementation and management of the Cloud Computing solution. The solution implementation may be done in iterative phases, through a continuous transition of the data, services and processes towards cloud, with the eventual return from cloud to operations internally hosted. It is performed based on some continuous evaluations of the cloud technology benefits upon the university. At the same time, implementation supposes establishing a flexible program of risk management (for treating the informational risks in continuous growth) (ISACA, 2009), testing the solution performance and implementation management.

The migration of the data, services and processes towards the cloud platform must be done based on some well-defined models/strategies. Each migration model assumes specific objectives to be achieved, according to the organization policy, control and information security (Mircea et al., 2011). Data migration must be performed by keeping an optimum balance between the data accuracy, migration speed, nonfunctioning time and minimum costs. At the organization level there must be a management model that includes policies regarding security, management of the applications and infrastructure, management of the risks and the continuous evaluation of the Cloud Computing solution (Mircea et al., 2011). An efficient management is essential for any program of quality management. It supports the proactive assurance of quality by measuring and improving processes, procedures and services performed.

\section{Conclusions}

Despite its critics and drawbacks, it seems that Cloud Computing is here to stay. Present economic situation will force more and more organizations at least to consider adopting a cloud solution. Universities have begun to adhere to this initiative and there are proofs that indicate significant decreasing of expenses due to the implementation of cloud solutions.

The aim of our work was to identify the particularities of using Cloud Computing within higher education. Mainly, we have considered the risks and benefits of cloud architecture and proposed a cloud adoption strategy proper for universities. An analysis of the data and the main activities that exist within a university was the starting point for 
choosing a cloud model that should take into account the special security requirements of higher education and the available cloud solutions as well. Future research will include a study regarding the level of acceptance and the implementation effects of Cloud Computing in Romanian universities.

\section{Acknowledgement}

This work was supported by CNCSISUEFISCSU, project PN II-RU (PD), "Modern Approaches in Business Intelligence Systems Development for Services Oriented Organizations Management", code 654/2010, contract no. 12/03.08.2010, project manager - Marinela Mircea.

\section{References}

Bozzelli, T. (2009). "Will the Public Sector Cloud Deliver Value? Powering the Cloud Infrastructure," CISCO. [Online], [Retrieved October 5, 2010],

http://www.cisco.com/web/strategy/docs/g ov/2009_cloud_public_sector_tbozelli.pdf

Bristow, R., Dodds, T., Northam, R. \& Plugge, L. (2010). "Cloud Computing and the Power to Choose," EDUCAUSE, [Online], [Retrieved October 5, 2010],

http://www.educause.edu/EDUCAUSE+Revi ew/EDUCAUSEReviewMagazineVolume45/C loudComputingandthePowertoCho/205498

Brunette, G. \& Mogull, R. (2009). "Security Guidance for Critical Areas of Focus on Cloud Computing," Cloud Security Alliance. [Online], [Retrieved October 5, 2010], http://www.cloudsecurityalliance.org/guida nce/csaguide.v2.1.pdf

Catteddu, D. \& Hogben, G. (2009). "Cloud Computing: Benefits, Risks and Recommendations for Information Security," European Network and Information Security Agency. [Online], [Retrieved October 5, 2010],

http://www.enisa.europa.eu/act/rm/files/d eliverables/cloud-computing-riskassessment
Ercan, T. (2010). "Effective Use of Cloud Computing in Educational Institutions," Procedia Social and Behavioral Sciences, 2, 938-942;

Golden, B. (2010). "What Cloud Computing Can Do for Higher Education," CXO Media Inc.

Goldstein, P. J. (2009). "Alternative IT Sourcing Strategies: From the Campus to the Cloud," EDUCAUSE Center for Applied Research. [Online], [Retrieved October 5, 2010],

http://net.educause.edu/ir/library/pdf/EKF /EKF0905.pdf;

ISACA (2009). "Cloud Computing: Business Benefits, With Security, Governance and Assurance Perspectives," SearchSecurity.com, 1-10

Ivan, I., Vintilă, B., Ciurea, C. \& Doinea, M. (2009). "The Modern Development Cycle of Citizen Oriented Applications," Studies in Informatics and Control, 18 (3), 263-270

Jitterbit (2009). "Five Integration Tips to Cloud Computing Success," Jitterbit, Inc. [Online], [Retrieved October 5, 2010], http://www.prweb.com/pdfdownload/2326 314.pdf

Katz, R., Goldstein, P. \& Yanosky, R. (2010). "Cloud Computing in Higher Education," EDUCAUSE. [Online], [Retrieved October 5, 2010], http://net.educause.edu/section_params/co nf/CCW10/highered.pdf

Katz, R. N,, Goldstein, P. J. \& Yanosky, R. (2009). "Demystifying Cloud Computing for Higher Education," EDUCAUSE. [Online], [Retrieved October 5, 2010], https://pantherfile.uwm.edu/mzwoo/public /cloudcomputing/ERB0919.pdf

Kavis, M. (2009). "A Move to Cloud Computing Should Involve SOA and BPM," TechTarget, CIO News. [Online], [Retrieved October 5, 2010], 
http://searchcio.techtarget.com/news/colu mn/0,294698,sid182_gci1355577,00.html

Lazowska, E., Lee, P., Elliott, C. \& Smarr, L. (2008). "Infrastructure for Escience and Elearning in Higher Education," Computing Community Consortium. [Online], [Retrieved October 5, 2010],

http://www.cra.org/ccc/docs/init/Infrastru cture.pdf

Luther, M. (2009). "Federated Key Management as the Basis for Secure Cloud Computing," SC Magazine

McCREA, B. (2009). "IT on Demand: The Pros and Cons of Cloud Computing in Higher Education," Campus Technology. [Online], [Retrieved October 5, 2010], http://campustechnology.com/Articles/200 9/08/20/IT-on-Demand-The-Pros-and-Consof-Cloud-Computing-in-Higher-

Education.aspx?Page $=1$

Mcirvine, S. (2010). "Making Cloud Computing Safe Trust, Security, Resiliency, Availability and Complexity," IBM Corporation. [Online], [Retrieved October 5, 2010],

https://www950.ibm.com/events/wwe/grp /grp004.nsf/vLookupPDFs/Security\%20\&\% 20Cloud\%20PCTY\%20\%20McIrvine/\$file/S ecurity $\% 20 \& \% 20$ Cloud $\% 20$ PCTY\%20$\% 20$ McIrvine.pdf

Mircea, M.(2010). "SOA, BPM and Cloud Computing: Connected for Innovation in Higher Education," 2010 International Conference on Education and Management Technology (ICEMT 2010), November 2-4, 2010, Cairo, Egypt, ISBN: 978-1-4244-86175 ;

Mircea, M. \& Andreescu, A. J. (2010). "Agile Systems Development for the Management of Service Oriented Organizations," 11th International Conference on Computer Systems and Technologies, CompSysTech'10, Sofia, Bulgaria, 17-18 June 2010, ISBN: 9781-4503-0243-2, 341-346;
Mircea, M., Ghilic-Micu, B. \& Stoica, M. (2010). "Combining Knowledge, Process and Business Intelligence to Delivering Agility in Collaborative Environment," 2010 Spotlight on Business Intelligence, Future Strategies Inc. \& Workflow Management Coalition, Florida;

Mircea, M., Ghilic-Micu, B. \& Stoica, M. (2011). "Combining Business Intelligence with Cloud Computing to Delivery Agility in Actual Economy," Journal of Economic Computation and Economic Cybernetics Studies, in press;

Nicholson, J. (2009). “Cloud Computing's Top Issues for Higher Education," University Business Solution for Higher Education Management. [Online], [Retrieved October 5, 2010],

http://www.universitybusiness.com/viewart icle. $\operatorname{aspx}$ ?articleid $=1342 \& \mathrm{p}=4 \# 0$

NIST, (2009). "Presentation on Effectively and Securely Using the Cloud Computing Paradigm v25," [Online], [Retrieved August 29, 2009],

http://csrc.nist.gov/groups/SNS/cloudcomp uting/cloud-computing-v25.ppt

Patterson, D. (2010). “Cloud Computing and the RAD Lab," UC Berkeley, Reliable Adaptive Distributed Systems Lab," [Online], [Retrieved October 5, 2010], http://www.mvdirona.com/jrh/TalksAndPa pers/PattersonMSCloudComputingRADLab.p df

Pocatilu, P., Alecu, F. \& Vetrici, M., (2009). "Using Cloud Computing for E-Learning Systems," Recent Advances on Data Networks, Communications, Computers, ISBN: 978-960-474-134-2, [Online],

[Retrieved October 5, 2010], http://www.wseas.us/elibrary/conferences/ 2009/baltimore/DNCOCO/DNCOCO-06.pdf

SafeNet, (2010). "SafeNet Solutions Secure Cloud Computing Deployments," SafeNet, Inc, [Online], [Retrieved October 5, 2010], http://www.safenetinc.com/About_SafeNet/ 
News_and_Media/News_and_Media_Items / 2 $010 /$

SafeNet Solutions Secure_Cloud_Computing Deployments.aspx

Sasikala, S. \& Prema, S. (2010). "Massive Centralized Cloud Computing (MCCC) Exploration in Higher Education," Advances in Computational Sciences and Technology, 3 (2), 111-118;

Sheelvant, R. (2009). "10 Things to Know about Cloud Computing Strategy," IT Strategy Spínola, M. (2009)," An Essential Guide to Possibilities and Risks of Cloud Computing'. [Online], [Retrieved October 5, 2010],

http://www.mariaspinola.com

Sultan, N. (2010). "Cloud Computing for Education: A New Dawn?," International Journal of Information Management, 30, 109116

Thomas, P. Y. (2009). "Cloud Computing: A Potential Paradigm for Practicing the Scholarship of Teaching and Learning," [Online], [Retrieved October 5, 2010], http://www.ais.up.ac.za/digi/docs/thomas_ paper.pdf

Thorsteinsson, G., Page, T. \& Niculescu, A. (2010). "Using Virtual Reality for Developing Design Communication," Studies in Informatics and Control, 19 (1), 93-106

Tout, S., Sverdlik, W., \& Lawver, G. (2009). "Cloud Computing and its Security in Higher Education," Proc ISECON, v26 (Washington DC): §2314, EDSIG, [Online], [Retrieved October 5, 2010]

http://proc.isecon.org/2009/2314/ISECON. 2009.Tout.pdf

Wyld, D. C. (2009). "Cloud Computing 101: Universities are Migrating to The Cloud for Functionality and Savings," Computer Sight. [Online], [Retrieved October 5, 2010], http://computersight.com/programming/clo ud-computing-101-universities-aremigrating-to-thecloud-for-functionality-and-savings/ 